\title{
ENUNCIAÇ̃̃ES PERFORMATIVAS DE TREINADORES DE VOLEIBOL SOBRE A PARTICIPAÇÃ̃O DE MULHERES TRANSEXUAIS ATLETAS NO NAIPE FEMININO
}

\author{
PERFORMING ENUNCATIONS OF VOLLEYBALL COACHES ON THE PARTICIPATION OF MALE-TO-FEMALE \\ ATHLETES IN WOMEN'S TEAMS
}

\section{RESUMO}

Este artigo tem por objetivo discutir como treinadores de voleibol, das categorias profissional e amadora do estado do Rio de Janeiro, performatizam enunciações sobre a presença de mulheres transexuais atletas em equipes do naipe feminino. Buscamos diálogo com os estudos pós-estruturalistas, sobretudo nas teorizações de Jacques Derrida e Judith Butler, pelas noções de performatividade da linguagem e performatividade de gênero. Além disso, realizamos a produção de narrativas com os treinadores pelos princípios de Leonor Arfuch e Jorge Larrosa, na operacionalização de entrevistas dialógicas por meio de conversas. Os treinadores enunciaram sentidos diversos, que remetiam ao preconceito e não aceitação das jogadoras nas equipes de voleibol, em particular os que atuavam na categoria profissional, como da inclusão das mesmas, ainda que dentro de determinados parâmetros. Acreditamos que novas pesquisas sobre a participação de atletas transexuais no esporte podem tensionar e constituir novas performatizações discursivas sobre o tema.

Palavras-chave: Transexual. Voleibol. Performatividade.

\begin{abstract}
This article aims to discuss how volleyball coaches, from the professional and amateur categories of the state of Rio de Janeiro, perform statements about the presence of male-to-female athletes in women's teams. We seek dialogue with post-structuralist studies, especially in the theorizations of Jacques Derrida and Judith Butler, for the notions of language performativity and gender performativity. In addition, we carried out the production of narratives with the coaches according to the principles of Leonor Arfuch and Jorge Larrosa, in the operation of dialogic interviews through conversations. The coaches enunciated different meanings, which referred to the prejudice and non-acceptance of the players in the volleyball teams, in particular those who worked in the professional category, such as their inclusion, even if within certain parameters. We believe that new research on the participation of male-tofemale athletes in sport can tense and constitute new discursive performances on the subject.
\end{abstract}

Blena Marinho

Universidade do Estado do Rio de Janeiro, Brasil. blenamarinho@hotmail.com

Leandro Brito

Universidade do Estado do Rio de Janeiro, Brasil. teofilo.leandro@gmail.com

Silvio Telles

Universidade do Estado do Rio de Janeiro, Brasil. telles.ntg@terra.com.br 
Keywords: Male-to-female. Volleyball. Performativity.

\section{Introdução}

Diante de um cenário tão vitorioso construído pelo voleibol brasileiro nos últimos anos, o esporte tem ganhado cada vez mais popularidade no país encontrando adeptos/as nas diversas camadas sociais e, sobretudo, sendo um espaço aberto para a participação de pessoas de diferentes identificações de gênero e orientações sexuais, ou seja, o voleibol sendo considerado um desporto de modelo híbrido no Brasil (COELHO, 2009). Neste contexto, não se pode ignorar a também crescente e recente discussão sobre a participação de mulheres atletas de voleibol que transitaram de gênero e toda polêmica causada por esse fenômeno no campo mais amplo do esporte.

No âmbito amador, em 2017, Isabelle Neris foi a primeira mulher transexual brasileira atleta autorizada a participar de equipes de voleibol no naipe feminino,

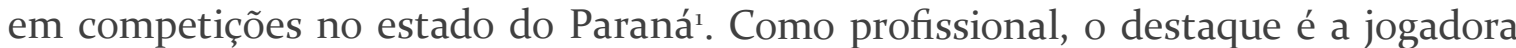
Tifanny Abreu, atleta da equipe de Bauru desde a temporada 2017/2018. Tifanny repercute na mídia por ser a primeira mulher transexual atleta profissional a receber autorização do Comitê Olímpico Internacional (COI) e da Federação Internacional de Voleibol (FIVB) para atuar no naipe feminino (GARCIA; PEREIRA, 202o), dividindo opiniões acerca de seu desempenho nas quadras da superliga feminina brasileira.

A discussão sobre a participação de Tifanny na superliga se tornou mais acalorada após o médico Paulo Zogaib, professor de medicina esportiva da Universidade Federal de São Paulo, afirmar que apenas o controle dos níveis de testosterona não tiraria a maior vantagem que ela tem sobre as mulheres cisgêneras em quadra ${ }^{2}$. Assim, após uma sequência de notícias que contrariavam as posições de Zogaib, legitimando cientificamente a permanência de Tifanny no vôlei feminino e de uma então possível convocação para seleção brasileira feminina de voleibol, a exatleta Ana Paula Henkel escreveu uma carta direcionada ao COI, à FIVB, ao Comitê Olímpico Brasileiro (COB) e à Confederação Brasileira de Voleibol (CBV), publicada em sua coluna no jornal Estadão ${ }^{3}$, expondo sua indignação em relação à presença de mulheres atletas que transitaram de gênero no contexto do esporte feminino. A carta de Ana Paula teve o apoio de várias jogadoras de voleibol em suas redes sociais e em entrevistas, como de uma das principais jogadoras da atual seleção brasileira feminina de vôlei: Tandara Caixeta. A jogadora também afirmou não concordar com a participação de Tifanny no naipe feminino, por afirmar que a atleta teve uma

1 Isabelle Neris, a primeira atleta transexual registrada em um time feminino no país. Disponível em: < https://bit.ly/3fFesZc >. Acesso em: 7 de ago. 2020.

2 Caso Tifanny: só controle de testosterona não tira a vantagem. Disponível em: $<$ https://bit.ly/2PBJorT >. Acesso em: 7 de ago. 2020.

3 Carta aberta ao COI. Disponível em: < https://bit.ly/31ybHnd >. Acesso em: 7 de ago. 2020. 
formação como homem em grande parte da vida, obtendo, assim, maiores vantagens em relação às mulheres cis, como maior massa muscular, força e pulmões maiores ${ }^{4}$.

Antes de Ana Paula e Tandara tecerem tais enunciações, o atual técnico da seleção brasileira feminina de voleibol, José Roberto Guimarães, expôs sua opinião em relação ao caso. O técnico se mostrou positivo à presença de Tifanny dentro do voleibol feminino e cogitou até uma possível participação da atleta na seleção em futuras competições ${ }^{5}$, fato que, posteriormente, não ocorreu, pois a FIVB anunciou a criação de um grupo de trabalho com o objetivo de estudar e definir critérios de elegibilidade de atletas transexuais nas competições internacionais ${ }^{6}$. Mais recentemente, José Roberto Guimarães reiterou sua posição em relação à convocação de Tifanny para a seleção, atrelando a chamada da atleta para os treinamentos a estes estudos e critérios que estão sendo desenvolvidos pela FIVB. Entretanto, a jogadora afirmou não acreditar nessa convocação, justificando-se pela questão da idade avançada frente a atletas mais jovens ${ }^{7}$.

Esses estudos promovidos pela FIVB, pautam-se nas exigências de elegibilidade que o COI chancelou no ano de $2015^{8}$ para a participação de atletas transexuais em competições esportivas oficiais. O COI, por meio de uma comissão de pesquisadores/as, médicos/as, entre outros/as profissionais, elegeu critérios para a inclusão de atletas transexuais nos naipes com o qual identificam-se em relação ao seu gênero. Esta comissão tomou como base a pesquisa de Harper (2015), que realizou uma investigação sobre tempos de corridas de atletas transexuais em comparação com os tempos dos naipes feminino e masculino e, conforme os resultados, determinou que homens transexuais possam participar dos eventos esportivos sem nenhuma restrição e que as mulheres transexuais precisam ter a quantidade de testosterona controlada no sangue (abaixo de 1onmol/L) por, no mínimo, um ano, excluindo a necessidade de cirurgia de transgenitalização. Cabe destacar que, entre as normas de elegibilidade criadas pelo COI - item 2.1 -, ao transitar de gênero o/a atleta não poderá mudar a identificação por quatro anos. Ainda assim, ignorando estas diretrizes, projetos de lei circularam nas Assembleias Legislativas de São Paulo e do Rio de Janeiro entre 2019 e 2020, visando instituir o sexo biológico como "único critério" para definição do gênero de competidores/ as em eventos esportivos oficiais em âmbito estadual. Mais recentemente, uma deputada federal também propôs um projeto em âmbito nacional9.

4 Respeito, mas não concordo com ela no feminino. Disponível em: $<$ https://glo.bo/2DLwv2m >. Acesso em: 7 de ago. 2020.

5 Técnico da seleção, José Roberto diz que convocaria Tifanny: "Elegível pra jogar". Disponível em: < https://glo.bo/3krkgxh >. Acesso em: 7 de ago. 2020.

6 Tifanny fica fora da seleção de vôlei, mas não por opção de Zé Roberto. Disponível em: < https://bit. ly/31u2VqC >. Acesso em: 7 de ago. 2020.

7 Tifanny agradece elogio de Zé Roberto, mas não crê mais em convocação para seleção. Disponível em: $<$ https://glo.bo/2DK59df >. Acesso em: 7 de ago. 2020.

8 IOC Consensus Meeting on Sex Reassignment and Hyperandrogenism November 2015. Disponível em: $<$ https://bit.ly/2XCjZJW >. Acesso em: 20 de out. 2019.

9 Deputada bolsonarista quer lei para barrar trans em equipes femininas. Disponível em: < https://bit. 
Buscando problematizar tais questões, trazemos a teórica feminista Judith Butler, que contesta a premissa de que o sexo é natural e o gênero é cultural pela afirmação de que o gênero é tão fixo quanto o sexo, quando reconhecido apenas dentro do binarismo masculino/feminino e coerente com a arbitrariedade da identificação sexo-gênero-desejo. A autora postula que o sentido de ser homem não deva se aplicar exclusivamente a corpos tidos como masculinos ou que o termo mulher interprete somente corpos femininos, assim, tal abertura possibilitaria que "homem e masculino podem, com facilidade, significar tanto um corpo feminino e masculino, e mulher e feminino, tanto um corpo masculino como um feminino" (BUTLER, 2015a, p. 26).

Desta maneira, a identificação do gênero, para Judith Butler, é performativa. A reiteração das normas de gênero, por aspectos linguísticos-discursivos, busca enquadrar os sujeitos como masculinos e femininos dentro de um quadro binário e articulado à heterossexualidade reprodutora (BUTLER, 2015a). Entretanto, tal processo se desenvolve de maneira contingente, o que possibilita o fracasso do suposto enquadramento binário.

[...] dizer que o gênero é performativo é dizer que ele é um certo tipo de representação; o "aparecimento" do gênero é frequentemente confundido com um sinal de sua verdade interna ou inerente; o gênero é induzido por normas obrigatórias que exigem que nos tornemos um gênero ou outro (geralmente dentro de um enquadramento estritamente binário); a reprodução do gênero é, portanto, sempre uma negociação com o poder; e, por fim, não existe gênero sem essa reprodução das normas que no curso de suas repetidas representações corre o risco de desfazer ou refazer as normas de maneiras inesperadas [...] (BUTLER, 2018, p. 39).

A teorização da performatividade da linguagem, central na noção da performatividade de gênero, foi desenvolvida pela leitura desconstrutora da teoria dos atos de fala do filósofo John Austin, realizada por Jacques Derrida e a leitura de Austin e Derrida por Judith Butler. Nessas leituras, Derrida (1991) e Butler (2009, 2018) descontroem algumas proposições de Austin (1990) afirmando o poder da linguagem na constituição dos sentidos que circulam socialmente, por meio de sua repetição e reiteração contínuas. Um enunciado performativo, nas palavras de Derrida (1991, p. 27) "não descreve algo que existe fora da linguagem e antes dela. Produz ou transforma uma situação, opera [..]. O performativo é uma 'comunicação' que não se limita essencialmente a transportar um conteúdo semântico já constituído e vigiado por uma verdade [...]". Nesta mesma direção, Butler (2018, p. 35) destaca que a capacidade performativa da linguagem "faz alguma coisa acontecer ou traz algum fenômeno à existência” e que "a performatividade é um modo de nomear um poder

ly/33FmE9y >. Acesso em: 8 de jun. 2020. 
que a linguagem tem de produzir uma nova situação ou acionar um conjunto de efeitos".

Para Rodrigues (2020), a performatividade pode ser entendida como um operador político contemporâneo tido como uma herança da virada linguística e que sua potencialidade precisa ser funcional para o campo da ação política. Neste sentido, propõe três tempos de interpretação desta teorização pelo pensamento de Judith Butler. No primeiro tempo, que é a performatividade da linguagem, a autora aponta que o poder da linguagem passa a ser entendido como uma rede de referencialidades, cujo sentido se produz como efeito do discurso. Pensada como estratégia de poder sobre a realidade, a linguagem passa a ser uma forma muito específica de ação e, deste modo, mantém uma tensão permanente entre manutenção e subversão das normas, que conserva e ao mesmo tempo supera as regras que estabelece num jogo dialético. No segundo tempo, que seria a performatividade de gênero, a autora destaca o esvaziamento de toda e qualquer fundamentação das normas de gênero, que passam a ser compreendidas como convenções vazias de sentidos, como operações de poder sobre os corpos e pensando na (cis)heteronormatividade ${ }^{10}$ como elemento que constrói e orienta a materialidade destes corpos. No terceiro tempo, a performatividade dos corpos, há a tentativa de se pensar como os atos corporais se tornam performativos, o que pode-se entender pela performatividade corpórea nas manifestações públicas de massa e, ainda, a relação indissolúvel entre essas duas formas de performatividade anteriores, que para Judith Butler se sobrepõem e não são completamente distintas.

Desse modo, reconhecemos que enunciações sobre a participação de mulheres transexuais atletas no contexto do voleibol podem produzir potentes efeitos de realidade pelas ubíquas disputas de sentidos que constituem os espaços esportivos frente a tais questões, pois como ainda coloca Butler (2018, p. 35), "a questão não é apenas que a linguagem atua, mas que atua de maneira poderosa”. Assim, este artigo tem como objetivo compreender como treinadores de voleibol, das categorias profissional e amadora do estado do Rio de Janeiro, performatizam enunciações sobre a presença de mulheres transexuais atletas em equipes do naipe feminino. Para isso, propomos a construção de dados por meio de produção de narrativas, que discutiremos com maiores detalhes na sequência.

10 Rodrigues (2019) faz uso em seu texto da noção de heteronormatividade, que diz respeito a imposição social da norma heterossexual atrelada ao binarismo de gênero. Nossa opção pela inserção do prefixo cis ao termo, que diz respeito a identificação cisgênera - pessoas que identificam-se com o gênero que lhes foi atribuído no momento do nascimento -, é um esforço conceitual de se pensar o termo cisheteronormatividade como forma de discutir as normas político-sociais, que impõem práticas e códigos cisgêneros a todas as pessoas (JARDIM, 2020). 


\section{Caminhos metodológicos}

Para a produção dos dados, operacionalizamos entrevistas que postulamos próximas, em sua fundamentação teórica, aos estudos pós-estruturalistas. Neste contexto, conforme já mencionamos, consideramos o pressuposto de que a linguagem, performativamente, atua na constituição dos sujeitos, seja na relação de forças discursivas que o nomeiam e o enquadram na norma, seja dentro da própria norma a possibilidade de que esse sujeito se ressignifique e se reconstitua para resistir, (re)existir e (in)surgir.

Fazemos coisas com palavras, produzimos efeitos com a linguagem e fazemos coisas para a linguagem, mas também a linguagem nos faz. A linguagem é o nome do que fazemos: ao mesmo tempo, "o que fazemos" (o nome de uma ação que realizamos de forma característica) e o que efetuamos, o ato e suas consequências (BUTLER, 2009, p. 25-26, tradução nossa"1).

Assim, consideramos preceitos de Arfuch (2010), cientista social argentina que se aproxima dos estudos pós-estruturalistas para discutir a entrevista e a produção de narrativas nas pesquisas em ciências humanas e sociais. Para esta autora, a entrevista é uma forma de narração que produz significados pela construção de enunciados, permitindo a possibilidade de apreender características significativas da cultura, num processo que é contingente e móvel. A entrevista é uma forma de indagação cuja versatilidade vai do informativo ao científico, do político ao íntimo, uma espécie de renovação cotidiana contínua do contato personalizado com o mundo (ARFUCH, 2010).

Nesta perspectiva, consideramos também o processo dialógico que ocorre entre entrevistador/a e entrevistados/as, buscando contestar relações de poder hierarquizadas por uma maior relação de horizontalidade entre os sujeitos na produção de informações na pesquisa.

[...] cada enunciação é dialógica, isto é, sempre implica um interlocutor (isto pode estar presente, ausente, fantasiado) e, portanto, o principal atributo é seu caráter de destino, modulado pela "presença" do outro (o destinatário), na medida em que ele argumenta para persuadi-lo, responde antecipadamente, antecipa suas objeções ("Como eu os imagino") a partir de uma hipótese sobre a sua capacidade de compreensão. [...]. A ideia de que o destinatário está presente na declaração, mesmo antes de poder emitir qualquer resposta, e mesmo independentemente

11 O texto em língua estrangeira é: "Hacemos cosas con palabras, producimos efectos con el lenguaje, y hacemos cosas al lenguaje, pero también el leguaje es aquello que hacemos. Lenguage es el nombre de lo que hacemos: al mismo tiempo "aquello" que hacemos (el nombre de una acción que llevamos a cabo de forma característica) y aquello que efectuamos, el acto y sus consecuencias". 
disso, sugere um protagonismo conjunto dos participantes na comunicação. Então a resposta pode ser vista como um processo ativo e simultâneo onde realmente acontece que todos falam todo o tempo. O diálogo é construído precisamente nesta adaptação mútua para falar não só para si, mas para outro (ARFUCH, 2010, p. 30-31).

Neste processo dialógico, também coadunamos com Larrosa (2003, p. 123) para reconhecer que uma conversa desenvolvida numa entrevista permite, mantém e não dissolve "a tensão entre as diferenças", o que faz com que se mantenha "também as dúvidas, as perplexidades, as interrogações", tornando tal processo instigante e atrativo no diálogo pesquisador/a e sujeitos pesquisados/as. O autor também afirma que "uma conversa pode manter as diferenças até o final, porém cada vez mais afinadas, mais sensíveis, mais conscientes de si mesmas... por isso uma conversa não termina, simplesmente se interrompe... e muda para outra coisa...", o que torna o processo de operacionalização de entrevistas menos hierarquizado. Desse modo, elencamos tópicos na operacionalização das conversas que constituíram as entrevistas para abordarmos a presença de mulheres transexuais atletas no contexto do esporte e problematizar a performatização dos enunciados proferidos pelos treinadores de voleibol.

Os sujeitos entrevistados, treinadores de voleibol das categorias profissional e amadora, foram escolhidos a partir da constituição de suas experiências profissionais frente ao trabalho com voleibol na cidade do Rio de Janeiro. As entrevistas foram realizadas no segundo semestre de 2018. Deste modo, apresentamos abaixo uma tabela com suas principais identificações.

Quadro 1 - Identificações dos sujeitos da pesquisa

\begin{tabular}{|c|c|c|c|c|c|c|}
\hline $\begin{array}{c}\text { Identificação do } \\
\text { técnico }\end{array}$ & $\begin{array}{c}\text { Naipe da } \\
\text { equipe }\end{array}$ & $\begin{array}{c}\text { Competições } \\
\text { principais }\end{array}$ & Nível & Idade & Gênero & $\begin{array}{c}\text { Tempo de } \\
\text { atuação }\end{array}$ \\
\hline Técnico profissional A & Fem. & $\begin{array}{c}\text { Campeonato } \\
\text { carioca, } \\
\text { Superliga, Copa } \\
\text { do Brasil }\end{array}$ & Profissional & 41 & Masc. & 20 anos \\
\hline Técnico amador A & Fem. & $\begin{array}{c}\text { Campeonato } \\
\text { carioca, } \\
\text { Superliga, Copa } \\
\text { do Brasil }\end{array}$ & Profissional & 52 & Masc. & 30 anos \\
\hline Técnico amador B & Fem. & $\begin{array}{c}\text { Liverj } \\
\text { Vôlei, Caxias } \\
\text { Open }\end{array}$ & Amador & 35 & Masc. & 7 anos \\
\hline
\end{tabular}

Fonte: dados da pesquisa. 
Na próxima seção, problematizaremos as enunciações dos treinadores sobre a participação de mulheres transexuais atletas no voleibol, destacando três eixos de interpretação, que significamos como potenciais efeitos performativos e arbitramos assim sua divisão por temas: Diretrizes do COI; Presença de mulheres transexuais nas equipes; Mulheres transexuais versus Mulheres cisgêneras no voleibol.

\section{Diretrizes do COI}

Problematizamos como um dos eixos das conversas com os técnicos, gerados pelas entrevistas, as diretrizes elaboradas pelo COI no ano de 2015, já mencionada aqui no artigo, que permitiram a participação de atletas transexuais nos naipes com o qual se identificam. Ao serem interpelados sobre as diretrizes, os treinadores profissionais se colocaram contrários a tal normativa, justificando-se pelas seguintes afirmações:

Eu acho que ela não deveria ser liberada para participar, que deveria haver uma competição trans pra ela jogar, com pessoas com o nível de força dela. Se elas não querem jogar com homem, onde elas deveriam jogar? Tem que ter uma liga trans (Técnico profissional A).

Pessoas que têm uma formação masculina e que nos esportes onde a força, além da técnica, é predominante, uma atleta trans vai ter vantagem, então acho que nada mais justo ele competir com pessoas do mesmo sexo, do mesmo padrão. O sexo ele transformou, ok. Mas do mesmo padrão físico né? Da mesma formação é... de nascimento e não opção (Técnico profissional B).

As falas proferidas pelos treinadores além de desconsiderarem por completo os estudos desenvolvidos pelo COI, enunciando uma suposta vantagem da força física de mulheres transexuais atletas, apontam como resolução do problema a criação de uma "liga trans" para absorver estas jogadoras. Sabe-se que não existe a possibilidade, no atual cenário ou em um cenário hipotético, da criação de uma liga de voleibol para mulheres atletas que transitaram de gênero. Conforme o estudo de Jones et al. (2017), apenas 1,1\% de toda a população mundial é composta por mulheres transexuais e $0,8 \%$ composta por homens transexuais. Neste contexto, precisamos considerar dentro desse $1,1 \%$ da população mundial, afetações por idade, classe social e a inserção destas pessoas no ambiente esportivo profissional. No alto rendimento do voleibol, temos conhecimento, além de Tifanny Abreu atuando em ligas profissionais femininas de voleibol, da espanhola Omy Perdomo ${ }^{12}$, que atua na superliga de seu

12 A primeira transexual a jogar na elite do vôlei espanhol. Disponível em: $<$ https://bit.ly/3klDOid >. Acesso em: 7 de ago. 2020. 
país, ou seja, um quantitativo ínfimo para a criação de uma liga de voleibol específica para mulheres transexuais.

Também consideramos as enunciações do treinador profissional B bastante preconceituosas, em particular do ponto de vista do não reconhecimento. O treinador remete-se à atleta, no caso Tifanny Abreu, no pronome masculino desconsiderando sua identificação como mulher. Nesta discussão, trazemos Bento (2014) que nomeia de cidadania precária uma dupla negação da condição humana e de cidadão/cidadã de sujeitos que carregam no corpo certas marcas segregatórias e excludentes. Essa dupla negação está historicamente assentada nos corpos de mulheres, de negros/as, de lésbicas, gays e, sobretudo, de pessoas transexuais. Assim, cada um desses corpos teve que se construir como um corpo político, entretanto o reconhecimento político, econômico e social se processa de forma lenta e descontínua, conforme constatamos nas enunciações do treinador B.

Butler (2014), nesta mesma direção, afirma que a norma governa inteligibilidades, autorizando que a permissão de determinadas práticas e ações sejam reconhecidas como tais, impondo uma grelha de legibilidade sobre o social e definindo os parâmetros do que será e do que não será reconhecido como domínio deste social. Assim, conforme a fala do treinador B, o não reconhecimento da identificação de Tifanny como mulher no espaço do voleibol, reitera em seu discurso uma cidadania precária vivenciada pela atleta e a naturalização de práticas que, performativamente, criam realidades de impedimento de sua atuação no esporte, ainda que as normas legais permitam sua participação: "se a norma confere inteligibilidade ao campo social e normatiza esse campo para nós, então estar fora da norma é continuar, em certo sentido, a ser definido em relação a ela" (BUTLER, 2014, p. 253).

As taxas hormonais também foram um ponto levantado pelo treinador:

Eu acho que, primeira coisa: tem que ter um controle das taxas hormonais, feito de uma forma aberta e clara. Por exemplo, no caso da Tiffanny, eu não vejo isso. O COI liberou, mas só que quem libera pra competições internacionais é a federação internacional. E no caso a Tiffanny, não está liberada, mas a confederação aqui liberou, por uma questão humanitária, ok. Acho ótimo. Mas, quando eu penso em restrições, eu acho que deveria haver uma discussão porque isso é uma coisa recente [...] (Técnico profissional $B)$.

O técnico profissional $B$ também aponta que a transição de gênero na adolescência, iniciando o tratamento hormonal nesta fase, minimizaria as supostas "vantagens" físicas de mulheres atletas trans:

[...] se transformar na adolescência, antes da formação adulta, pode ser um caminho (Técnico profissional B). 
Neste contexto, sabe-se que as taxas hormonais já são controladas pelas equipes profissionais, pois esta é uma norma da CBV para a presença de Tifanny na superliga. Uma mulher transexual, em uma equipe feminina, precisa apresentar níveis de testosterona sanguínea abaixo de $10 \mathrm{nmol} / \mathrm{L}$, conforme as diretrizes sancionadas pelo COI e já citadas neste artigo. O controle é realizado constantemente pelas equipes esportivas.

Já a afirmação de que a transição ocorra na adolescência, conforme o treinador profissional B enuncia, apontamos que não existem estudos que comprovem tal premissa. Nesta discussão, Kennedy (2010) aponta que a transição de gênero não deve ser associada necessariamente a cirurgias, utilização de hormônios, alterações do nome civil ou comportamentos específicos para que assim seja legitimada socialmente. A autora defende que o processo transição não pode indicar somente as alterações anatômicas, hormonais ou estéticas nos corpos dos sujeitos, mas processos subjetivos mais amplos. Entendemos que o processo de transição de gênero ainda gera discussões sobre a questão do rendimento físico, sobretudo numa mulher atleta, entretanto a contestação das pesquisas realizadas pelo COI precisa ser feita de maneira contextualizada e não por enunciações que remetem ao senso comum.

Paradoxalmente, o profissional, no diálogo, reconhece em certa medida tal ponto:

Não é simples. Eu entendo tanto quem concorda, como quem discorda, porque como é o primeiro caso aqui no Brasil, então é uma situação bem delicada e requer muito estudo, muita troca de opinião e de pesquisa, pra que realmente ninguém saia perdendo na história, é uma situação bem delicada (Técnico profissional B)

As enunciações contrárias dos técnicos às diretrizes elaboradas pelo COI para a participação de mulheres transexuais atletas no esporte, ainda que bastante frágeis do nosso ponto de vista, reiteram o não reconhecimento destas pessoas no campo social esportivo, produzindo assim efeitos que se materializam na contestação da presença de jogadoras transexuais nas equipes de voleibol, conforme discutiremos no próximo eixo de problematização.

\section{Presença de mulheres transexuais nas equipes}

As enunciações de cada técnico podem ser influenciadas pela oportunidade de trabalhar com uma atleta transexual, já que ter presença das mesmas e por todas as vivências proporcionadas por essas pessoas em uma equipe, acabam por contribuir decisivamente nos diferentes discursos presentes nas narrativas. Assim, foi perguntado a cada técnico sobre a presença de mulheres transexuais como jogadoras em suas equipes e, entre as respostas, os técnicos profissionais afirmaram 
não existir jogadoras transexuais em suas equipes, já nas equipes amadoras, existem jogadoras transexuais e, ainda, a possibilidade da inserção de mais uma nova atleta para a próxima temporada. Neste contexto, o técnico amador A discute a presença de atletas transexuais nas competições de voleibol em que participa:

Olha, eu particularmente nunca vi problema algum em relação a recepção de atletas trans nas competições. Na Liverjis tem uma equipe que tem uma atleta trans e ano que vem a nossa vai ser a segunda. E sinceramente, o que eu vejo é uma integração muito grande entre as atletas, entre as equipes. Isso passa assim como uma condição normal né?! O que de fato é! (Técnico amador A).

Diferente das falas dos treinadores das equipes profissionais, o técnico amador A não enuncia qualquer impedimento sobre a presença de uma mulher transexual como jogadora nas equipes de voleibol dos campeonatos amadores em que disputa e até coloca que sua equipe, no próximo ano, também terá uma atleta transexual. Para Butler (2018) pessoas que não performatizam seu gênero de maneira inteligível, recorrentemente, está em risco acentuado de assédio, patologização e violência, entretanto deslocamentos por ressignificações sociais diversas também apontam outros caminhos associados ao reconhecimento, conforme a enunciação do técnico amador A nos mostrou.

Um dos maiores símbolos de tensão no meio esportivo, além da quadra, é o vestiário e o tema emergiu no diálogo com o técnico amador B:

Então, assim, as meninas, elas não se trocam no vestiário né?! Elas já vêm com a parte de baixo já vestida né?! Então elas entram no banheiro só pra trocar a camisa. Então eu acho que elas trocam dentro da cabine, ou como é só a parte de cima, então a parte de cima automaticamente é igual das mulheres, então acho que até então não tem problema nenhum. Eu acho que até então nunca chegou nenhuma reclamação. Nunca chegou nada aos meus ouvidos (Técnico amador B).

O técnico da equipe amadora B frisa que a "parte de cima" de uma jogadora cisgênera é igual de uma jogadora transexual, logo, não vê problema que troquem de roupa juntas, além de relatar que não acredita que pudesse ter algum problema, porque crê que haja uma boa relação entre a atleta transexual e as atletas cisgêneras. Ainda assim, a articulação da coerência sexo-gênero é enunciada quando o técnico faz menção à questão de a genitália da atleta transexual não ser igual das atletas cisgêneras. $\mathrm{O}$ uso do banheiro/vestiário feminino por mulheres transexuais é uma questão ainda colocada em discussão nos contextos sociais, pela justificativa de que

13 A Liverj é a principal liga amadora de voleibol do estado do Rio de Janeiro. Página da Liverj: < https:// bit.ly/zadBHsg>. Acesso em: 7 de ago. 2020. 
poderiam causar constrangimento às mulheres cisgêneras, conforme Rios e Redasori (2015) afirmam. Para os autores, o uso de banheiros públicos é uma questão ainda problemática para pessoas transexuais, pois shoppings, academias, repartições públicas, empresas e diversos outros espaços coletivos separam os banheiros a partir de uma lógica binária atrelada ao sexo biológico e que, muitas vezes, não reconhece estas pessoas dentro de seus direitos sociais. Deste modo, concordamos com os autores no seguinte ponto:

A questão constitucional sobre o direito de transexuais femininas utilizarem banheiros públicos femininos é, sem sombra de dúvida, de alta relevância e inegável importância. Ela diz respeito não somente às pessoas diretamente atingidas, como também ao padrão de civilidade no convívio democrático que necessitamos construir, sem esquecer que marcaria uma involução nas diretrizes firmadas pelo próprio STF na ADPF n. 132. Ao exigir que os direitos fundamentais de dignidade humana, privacidade, liberdade e igualdade estejam livres de discriminação por identidade de gênero, ela afasta binarismos de gênero nutridos por percepções simplistas e superficiais e preconceituosos sobre sexo e sexualidade (RIOS; REDASORI, 2015, p. 217).

Na produção das narrativas emergiu uma discussão sobre como os familiares das atletas se sentiam em relação à presença de uma atleta transexual na equipe de suas filhas. Em paralelo à discussão, foi possível notar na fala do técnico amador B a confusão entre as identificações orientação sexual e identidade de gênero:

Até porque muitas delas são homossexuais né?! Então assim, eu não sei como é que é tratado, porque cada família é uma família né?! Tipo, cada um reage de uma forma diferente. Então eu não sei como a família delas reagiu com relação à homossexualidade delas e eu não sei se chega a ser uma coisa natural delas chegarem e comentarem a relação (Técnico amador $B$ ).

Com discursos diversos circulando na sociedade contemporânea, não nos surpreendemos com essa confusão, principalmente porque o conhecimento sobre esse campo se mostra cada vez mais em disputa na sociedade. Scott (2012) destaca que, entre o final dos anos de 1990 e início dos anos 2000, disputas de sentidos deflagram-se em torno do conceito de gênero que, inicialmente, significou-se como a relação social entre os sexos, mas que seus usos se tornaram cada vez mais imprecisos e disputados, sobretudo na arena política. Neste contexto, o conservadorismo afetou a compreensão da sociedade sobre termos como gênero, identidade de gênero, orientação sexual, entre outros, trazendo significações diversas nos contextos sociais, que iam desde sinônimo de mulheres à associação com a homossexualidade. 
Outro ponto de interpretação, diz respeito à ausência das temáticas de gênero e sexualidade nos cursos de formação docente, no caso de nossa discussão específica, a formação docente em Educação Física, como um campo dominado por disciplinas de cunho biológico e que carece bastante de discussões sobre questões socioculturais. Neste sentido, a ausência destas discussões, inegavelmente, impacta a atuação de professores/as de Educação Física no trato com questões relacionadas às diferenças em sua prática profissional, sobretudo aqueles/as que atuam no campo do esporte, pois "várias organizações do esporte também estão marcadas por características patriarcais, machistas e cisgêneras” (IWAMOTO, 2020, p. 314).

\section{Mulheres transexuais versus Mulheres cisgêneras no voleibol}

As narrativas também trouxeram significados relacionados às diferenças entre as atletas transexuais e cisgêneras nas enunciações dos treinadores. As questões biológicas/fisiológicas, assim como as questões socioculturais, foram a tônica das enunciações nas narrativas dos treinadores. No que tange a dominância das questões biológicas no esporte, o técnico amador B respondeu:

E vou voltar a falar, a olho nítido que a Tifanny é muito mais forte que as meninas que ela joga contra (Técnico profissional B).

Novamente a questão da suposta "vantagem física" é levantada numa enunciação e o treinador afirma acreditar que a jogadora Tifanny Abreu seja mais forte que as atletas cisgêneras na superliga. Já o técnico amador A enuncia um olhar mais tático sobre o rendimento de Tifanny:

Ela joga numa posição em que ela naturalmente é muito acionada durante o jogo, ejoga como oposta que é a viradora de bola principal de uma equipe e eu acho que nessa situação, os conceitos, eles acabam se misturando um pouco, porque se vocêfor comparar os números dela por exemplo, com os de outras jogaras da equipe dela, de fato ela vai sobressair, só que ai quando você compara os números dela com jogadoras da mesma posição de outras equipes, ela não sobressai tanto, entendeu? (Técnico amador A).

A visão deste treinador destoa, porque o mesmo justamente aponta para as questões tidas como qualitativas do jogo de voleibol e não somente para o aspecto técnico, que é recorrentemente interpretado pelo biológico. A pontuação de Tiffanny foi praticamente igual da oposta Tandara Caixeta, na temporada 2017/2018 ${ }^{14}$ da

14 Tandara x Tifanny: maiores pontuadoras da superliga duelam nesta sexta. Disponível em: < https:// glo.bo/3kquauE > Acesso em 7 de ago. 2020. 
superliga, e devemos relembrar que Tandara é uma atleta cisgênera. Apenas um dos técnicos disse que não trabalharia com uma transexual em sua equipe:

Eu acho que eu não teria uma mulher trans no meu time, pois eu não aceitaria. Porque eu acho que a Tiffanny jogar é burlar a regra e eu sou totalmente contra burlar os regulamentos (Técnico profissional A).

Nos questionamos sobre quais regras e regulamentos o técnico profissional A remete-se em sua fala, já que a instância máxima do esporte, o COI, regulamentou a participação de atletas transexuais nos naipes com o qual identificam-se em seu gênero, conforme já trouxemos aqui nesse texto. Nesta discussão, mencionamos que a condição politicamente induzida de não reconhecimento e marginalização vivida por certos sujeitos, fazendo com que os mesmos estejam mais suscetíveis à injúria, exclusões, violência e vulnerabilidade é nomeada por Butler (2015b) como vida precária. A autora afirma que há formas de distribuição da vulnerabilidade em que algumas pessoas encontram-se mais expostas que as outras e suas vidas não contam nos diferentes contextos sociais como uma vida vivível, pois "uma vida específica não pode ser considerada lesada ou perdida se não for primeiro considerada uma vida" (BUTLER, 2015b, p. 13).

Enquadramentos sociais diversos classificam vidas como não qualificadas como vidas, segundo Butler (2015b) e, deste modo, as mesmas nunca serão vividas e nem perdidas, em seu sentido pleno. Estes enquadramentos, baseados em relações de poder hierarquizadas, colocam os sujeitos em molduras, impondo-lhes a condição precária de vida, que pode ser maximizada para algumas pessoas e minimizada para outras, conforme os esquemas de inteligibilidade que ditam estas normas. A condição de que uma vida importa parte do pressuposto de que essa vida é uma vida vivível. Neste contexto, vidas de pessoas transexuais são vidas precárias, pois a luta por reconhecimento se mostra inesgotável em diferentes campos e o esporte é um deles.

\section{Considerações}

As enunciações dos treinadores de voleibol sobre a participação de mulheres transexuais atletas em equipes do naipe feminino, interpretadas pelas perspectivas pós-estruturalistas, em particular pela noção de performatividade da linguagem, mostrou as ubíquas disputas de sentidos que são travadas nas contingências contemporâneas e que constroem as significações de ordem política, participando assim da constituição das realidades sociais. Ao adentrarmos nossas análises no campo do esporte, nos deparamos com um terreno dominado e fundamentado pela biologia como uma estrutura sedimentada e que confere legitimidade de participação 
para homens e mulheres enquadrados/as no binarismo de gênero. Entretanto, as estruturas podem e devem ser desestabilizadas e, deste modo, a presença de atletas transexuais no esporte mobilizou novas configurações nestes espaços.

No contexto das narrativas, os técnicos de nível amador enunciaram falas mais positivas à presença destas jogadoras no espaço do voleibol. Lembramos que estes técnicos trabalham e jogam contra equipes compostas por atletas transexuais em suas esquipes. Provavelmente, por acompanharem mais de perto toda luta dessas jogadoras por reconhecimento ou, ainda, pela menor cobrança por resultados, característica que é mais marcante em uma competição profissional, as enunciações destes treinadores possibilitam a criação de realidades sociais mais inclusivas no âmbito do voleibol amador carioca.

Já as enunciações dos técnicos profissionais mostraram bastante resistência sobre a presença de mulheres transexuais como jogadoras, em particular da participação de Tifanny Abreu, mencionada recorrentemente pelos mesmos nas entrevistas. Neste contexto, o posicionamento contrário destes treinadores, dada a posição de poder e a visibilidade que os mesmos têm no espaço do voleibol, sobretudo na mídia esportiva, produzem significações de relevo e que podem contribuir para a manutenção do preconceito e do não reconhecimento destas jogadoras no contexto esportivo.

A complexa constituição discursiva da ordem social pode e deve favorecer à escuta de muitas e heterogêneas vozes que disputam significações sociais diversas e, deste modo, acreditamos que novas pesquisas sobre a participação de pessoas transexuais no esporte podem tensionar e constituir novas performatizações discursivas sobre o tema.

\section{Referências}

ARFUCH, Leonor. O espaço biográfico: dilemas da subjetividade contemporânea. Rio de Janeiro: Ed. UERJ, 2010.

AUSTIN, John. Quando dizer é fazer: palavras e ações. Porto Alegre: Artes Médicas, 1990.

BUTLER, Judith. Corpos em aliança e a política das ruas. Notas para uma teoria performativa de assembleia. Rio de Janeiro: Civilização Brasileira, 2018.

BUTLER, Judith. Lenguaje, poder e identidad. Madrid: Editorial Síntesis, 2009.

BUTLER, Judith. Problemas de gênero:feminismo e subversão da identidade. $8^{a}$ edição. Rio de Janeiro: Civilização Brasileira, 2015a. 
BUTLER, Judith. Quadros de guerra: quando a vida é passível de luto. Rio de Janeiro: Civilização Brasileira., 2015b.

BUTLER, Judith. Regulações do gênero. Cadernos Pagu, n. 42, p. 249-274, 2014. Disponível em: < https://bit.ly/33AlQ5H >. Acesso em: 8 de ago. 2020.

COELHO, Juliana. Voleibol: um espaço híbrido de sociabilidade esportiva. In: TOLEDO, Luiz Henrique; COSTA, Carlos Eduardo (Orgs.). Visão de jogo: antropologia das práticas esportivas. São Paulo: Editora Terceiro Nome, 2009, p. 75 - 93.

DERRIDA, Jacques. Limited inc. Campinas: Papirus, 1991.

GARCIA, Rafael Marques; PEREIRA, Erik Giuseppe Barbosa. A opinião de atletas e treinadores de voleibol sobre a participação de mulheres trans. Movimento, v. 26, 2020, e26068. Disponível em: < https://bit.ly/3jZD3df >. Acesso em: 5 de nov. 2020.

HARPER, Joana. Race times for transgender athletes. Journal of Sporting Cultures and Identities, v. 6, n. 1, 2015, p. 1-9. Disponível em: < https://bit.ly/2DPkoCX >. Acesso em: 8 de ago. 2020.

IWAMOTO, Thiago. Do mundo offline para o online: discursos em rede contra a inclusão de atletas transexuais. CSOnline - Revista Eletrônica de Ciências Sociais, n. 31, 2020, p. 301-323. Disponível em: < https://bit.ly/3poRl14 >. Acesso em: 5 de nov. 2020.

JARDIM, Juliana Gomes. Cis-heteronormatividade, MMA, Educação Física e sociedade. Movimentalidade. 2020. Disponível em: < https://bit.ly/37w1yKq >. Acesso em: 8 de ago. 2020.

JONES, Bethany Alice et al. Sport and transgender people: A systematic review of the literature relating to sport participation and competitive sport policies. Sports Medicine, v. 47, n. 4, 2017, p. 701-716. Disponível em: < https://bit.ly/2PCkJdz >. Acesso em: 8 de ago. 2020.

KENNEDY, Natasha. Crianças Transgênero: mais do que um desafio teórico. Revista Cronos, v. 11, n. 2, 2012, 4-41. Disponível em: < https://bit.ly/2PwIiV2 >. Acesso em: 8 de ago. 2020.

LARROSA, Jorge. A arte da conversa. In: SKLIAR, Carlos. Pedagogia (improvável) da diferença. E se o outro não estivesse aí? Rio de Janeiro: DP\&A, 2003, p. 211-216. 
RIOS, Roger Raupp; RESADORI, Alice Hertzog. Direitos humanos, transexualidade e “direito dos banheiros". Revista Direito e Práxis, v. 6, n. 12, 2015, p. 196-227. Disponível em: < https://bit.ly/2DwwVdl >. Acesso em: 8 de ago. 2020.

RODRIGUES, Carla. Escritas: filosofia e gênero. Rio de Janeiro: Ape’Ku Editora, 2020.

SCOTT, Joan. "Os usos e abusos do gênero". Projeto História. Revista do Programa de Estudos Pós-Graduados de História, v. 45, 2012, p. 327-351. Disponível em: < https:// bit.ly/2Z8ogKQ >. Acesso em: 8 de ago. 2020.

Recebido em 18/o1/2020.

Aceito em 16/11/2020. 